\title{
A Proposed Method for Eliminating Titles from Periodical Subscription Lists
}

\author{
Robert N. Broadus
}

A method is outlined for determining what periodical titles should be reviewed for cancellation by a university library. A list of candidates for elimination is gathered from titles with low citation counts as found in Journal Citation Reports. Reasons for starting with these lists are based on general findings in the use and citation studies' literature. It is recognized that some little-cited journals may be retained, and the principal reasons for retention are discussed.

large university library faces the need to trim the cost of its subscription list by 10 percent. What standards and evidence should be used in choosing the titles to cancel?

Among the criteria to consider are (1) cost of the journal, record keeping, claiming, storage, and binding; (2) convenience of obtaining elsewhere; (3) availability in another format, such as microform; (4) coverage of the title by indexes, abstracting services, and bibliographic databases; (5) language; (6) relevance to local needs; (7) number of useful articles published per year or per dollar; (8) amount of use received; and (9) ranking by library users. ${ }^{1}$ Woodward tabulated the relative importance assigned to each of eighteen different elements by 250 academic, research, and industrial libraries in Great Britain. ${ }^{2}$ Advice from patrons ranked first; measures of use in the library ranked second. Of course, use was inherent in the first element, as well as in some of the other seventeen, such as "cost per use."

Most librarians believe that journal use is an extremely important factor in the retention decision but realize that use studies are difficult to design and fairly expen- sive to conduct. Definitions of use are also sketchy. Is touching a use or must the volume be physically removed from the shelf? Does use assume that some reading, even skimming, has occurred? A journal "used" thirty times may produce as much "value" as one used sixty times. One session with the American Historical Review may occupy more time (and perhaps be worth more) than several uses of Time or even the National Lampoon. Use studies produce information of significant theoretical and practical value, but one cannot deny that they are costly and that their validity is less than ideal. In any event, they are most cost-effective when applied to an entire collection of journals or monographs. If the number of titles to be cancelled is small, it is most efficient to locate only the likely candidates and to ignore the others.

\section{IDENTIFYING TITLES \\ FOR CANCELLATION Use of Journal Citation Reports}

In large university libraries, especially in their departmental and professional school libraries, one might begin the process of identifying titles for cancellation by reviewing Journal Citation Reports (JCR),

Robert N. Broadus is professor in the School of Library Science at the University of North Carolina, Chapel Hill, North Carolina 27514. 
published by the Institute for Scientific Information (ISI) in connection with its Science Citation Index (SCI) and Social Sciences Citation Index (SSCI). (If ISI starts the JCR for the arts and humanities, the procedure proposed here will also be applicable for those areas.)

For the problem at hand, the most important information in the JCR is the ranking of each journal by the number of times its articles were cited by other journals. The $S S C I J C R$ is compiled from the SCI, SSCI, and Arts \& Humanities Citation Index database. ${ }^{3}$ In 1982, the JCR covered 6,600 source journals with citations. Articles in the 1980 and 1981 issues of one journal were cited 1,772 times in the 1982 source journals; articles in another journal were cited 810 times. In all, five journals received more than 700 citations. ${ }^{4}$ Listed in table 1 are some journals whose titles promise interest, but which received few citations. ${ }^{5}$ Approximately 130 periodicals received one citation or less (75 received none) in this list of 1,335 periodicals. For example, not one article in Soviet Sociology was cited by any of the 6,600 source journals.

By matching its current periodicals list against the $J C R$, a library might identify which 20 percent of its titles received the fewest citations. These periodicals might be reviewed for possible deselection.

\section{Rationale for Use of Journal Citation Reports}

Questions have been raised by several authorities as to whether citation counts are good indicators of periodical use or quality. Indeed, one well-known investigator, Colin Taylor, has remarked, "I have no confidence whatsoever in the ability of international citation data lists to predict the titles which should be rele- gated to storage in a particular library's situation." ${ }^{\prime 6}$ Although Taylor was speaking in an Australian context and of relegation rather than deselection, his opinion should still hold for the question under discussion here. Various studies have disputed the point, but the results of these investigations are difficult to interpret because of their contradictory conclusions. ${ }^{7}$ In some of the literature there is an implicit assumption that if citation counts and use counts differ, the citation-count method is suspect and the use-count method is valid. This assumption does not give sufficient weight to the following factors: (1) although important and helpful, use studies are difficult to conduct (note the controversy generated by the University of Pittsburgh study); and (2) use changes over time, despite the generally accepted principle that past use is the best predictor of future use. The use dictum holds because we do not have accurate predictors of any kind. We may never get them. With faculty still somewhat mobile and with academic programs subject to change in both content and enrollment, the use of a library in one year does not predict perfectly its use in another. Furthermore, the collection changes, and if the amount of use remains constant from one year to the next, the particular items used will be at least a little different. Here are some typical results from several use studies.

Pamela Tibbetts employed the sweep method to gather data on in-house use in a biomedical library. ${ }^{8}$ Two samples were gathered in the same month. Of 59 journals ranked highest in the first sample, only 33 were in the top 59 or so in the second sample. Since the library subscribed to 2,500 journals, the discrepancies were not great. Nevertheless, they indicate the imperfections of use studies as predictors.

Barbara Rice, who has studied journals

TABLE 1

\begin{tabular}{llccc}
\hline \hline Rank & \multicolumn{1}{c}{ Journal } & Citations Received in 1982 Source Journals & 1981 & 1980 \\
1118 & Mankind Quarterly & 2 & 1 & Total \\
1148 & Journal of Urban History & 1 & 1 & 3 \\
1201 & Middle East Review & 0 & 1 & 2 \\
1201 & American Journal of Criminal Law & 0 & 1 & 1 \\
1260 & Soviet Sociology & 0 & 0 & 1 \\
\hline
\end{tabular}


extensively, found only a +.66 rank-order correlation (high, but far from perfect) between use of the 25 most heavily consulted titles in successive semesters in the science library at SUNY-Albany. ${ }^{9}$ Of the 25 ranked highest in the first semester, 8 were not in the top 25 in the second semester. The fact that the library had 2,300 titles indicates a certain consistency of use during the two semesters, but agreement was far from perfect.

In the same study, Rice found a very low rank-order correlation between use of periodicals in the science library and their ranking in the 1975 JCR. While the ranks for some titles were remarkably similar on the two lists, there were notable exceptions. (Rice is very fair in her interpretation of this correlation, noting the difficulties of comparing the two lists. In a later article, Tony Stankus and Rice seem to give the findings more significance. $)^{10} \mathrm{Ta}-$ ble 2 shows some of the most glaring discrepancies listed by Rice. ${ }^{11}$

Psychology journals generally ranked high in local use, but not in the 1975 JCR. A part of the difference may be explained thus: the 1975 JCR included few source journals in education. This meant that the frequent citations from the psychology literature made by authors in education journals were missing. At the same time, education students are frequently referred to psychology journals. This explanation is given some weight when the psychology journals are checked in SSCI JCR for 1977 (the first $J C R$ published specifically in connection with the $S S C I$ ). As shown in the last column of table 2, the Journal of $A b$ normal Psychology ranked 4th at SUNYAlbany and 707th on the 1975 JCR list, but was 6th in the 1977 SSCIJCR. The American Journal of Psychiatry's ranking in the 1977 SSCI JCR is also closer to its use rank at Albany.
It is always possible for other factors to affect local use. Alexander Sandison reported that in papers written by MIT physicists, there were few references to Physical Review issues published before 1955 and significantly more references to subsequent years. ${ }^{12}$ The apparent reason for this peculiarity was that issues of the journal prior to 1955 were shelved in the basement. It seems likely that since these early volumes were cited less, they must have been consulted less.

Once all factors are considered, the low correlations often found between national citation data and local use are more understandable, and the role of citation analysis can be understood more clearly.

First, these correlations are usually slight when different populations of those using journals and those citing journals are compared. If references made by physicists are compared with journals used by physicists, the correlations are likely to be higher. Studies in a university library seldom measure the latter use because the clientele includes students and people from other disciplines, and even physicists may use material for "non-serious" purposes.

In particular disciplines where the population making citations would seem to have subject interests similar to those using the material in the library, the number of citations received by each journal parallels more closely its local use. Stankus and Rice $^{13}$ found that for several fields in the sciences, the position of journals ranked according to use corresponded closely to their ranks according to gross numbers of citations received over the years. In the field of geoscience the rank-order correlation was not as positive. Patterns were also less clear for mathematics journals, but the total amount of use received by them was small. In those subjects where

TABLE 2

\begin{tabular}{|c|c|c|c|}
\hline Title & $\begin{array}{c}\text { Use Rank } \\
\text { SUNY } \\
\text { Albany }\end{array}$ & $\begin{array}{l}\text { JCR } \\
\text { Rank } \\
1975 \\
\end{array}$ & $\begin{array}{c}\text { SSCIJCR } \\
\text { Rank } \\
1977^{*} \\
\end{array}$ \\
\hline $\begin{array}{l}\text { Journal of Abnormal Psychology } \\
\text { American Journal of Psychiatry } \\
\text { Archives of General Psychiatry } \\
\text { American Journal of Orthopsychiatry } \\
\text { American Journal of Mental Deficiency }\end{array}$ & $\begin{array}{r}4 \\
10 \\
13 \\
15 \\
23\end{array}$ & $\begin{array}{l}707 \\
261 \\
267 \\
917 \\
868\end{array}$ & $\begin{array}{r}6 \\
2 \\
3 \\
47 \\
53\end{array}$ \\
\hline
\end{tabular}

*Source: SSCI, JCR, 1977 
local use was high, the authors state, "Citation data correlates well, perhaps predictively, in titles that should be eliminated. ${ }^{\prime 14}$ In a study of chemical journals, Rice also found a high correlation between library use and JCR rank. ${ }^{15}$

Second, where the population using a library is interested mainly in English language material, and where sources used for citation counts include a large proportion of foreign language publications, there are more likely to be discrepancies. It would be interesting to have JCR solely for English-language sources.

Third, local use will differ from national use to some extent. Wiberley raised the question: what is the better predictor of which journals will be cited in the future by faculty in social work-journals previously cited by that faculty or journals ranked by citations in national citation databases? ${ }^{16}$ Of the thirty-three journals most heavily cited in the 1971-74 issues of three national periodicals, twenty-four were cited three or more times by local writers in 1975-78. For the thirty titles that were cited most frequently, the difference was small but clear in favor of the local sources. ${ }^{17}$ The difference may not be great enough, however, to justify separate studies of local citations.

Fourth, there are other reasons for some of the low correlations between journals cited by scholars and those used by a general clientele. For example, the scholar's approach to articles is not the same as that used by other readers. In looking for library materials, scholars frequently start with bibliographic references in monographs or journals; students are more likely to begin with indexes such as the Reader's Guide to Periodical Literature.

Two recent studies completed at the University of Illinois underscore these differences. Patricia Stenstrom and Ruth McBride asked social science faculty: "When you come to the library to find a specific article, how often do you find the reference by consulting [any of seven sources]?'"18 Heading the list were bibliographies/footnotes in journals and bibliographies/footnotes in books. At the same university, another research study-with over 50 percent of the subjects undergraduates and 9 percent faculty-found that the sources of the references sought in the library presented quite a different pattern: only 8 percent of the users indicated "bibliography in book," and only 7 percent credited any one of the following: bibliography in journal, footnote in book, and footnote in journal. ${ }^{19}$ From this evidence it can be seen why citation counts tend to correlate more strongly with faculty and research use than with use by other members of the academic community. In his recent monograph, Paul Metz notes a certain similarity between citation data and monograph usage by graduate students and faculty. ${ }^{20}$

If proper allowances are made, counts based on the JCR can be almost as good as expensive local studies for predicting use of periodicals in a given library. Furthermore, for many research libraries a journal that provides relevant material for faculty and students in their scholarly pursuits is preferable to one that people merely thumb through. It is to the former that citation studies relate.

\section{APPLICATION}

Assuming that citation studies are valid, it would be a mistake to cancel a journal for this kind of screening only because it is not cited frequently. Low-citation-count journals are just candidates for deselection. While the policies of local libraries may differ in this respect, there are other factors that most academic libraries should consider.

1. A title may rank high on another list of cited publications. Psychology journals, for instance, do not as a rule show up well where the sources of citations are journals in the physical or biological sciences. If a library collects mainly science periodicals but has some users who are interested in psychology, it is obviously best to check the JCR for both subject areas.

2. A little-cited periodical might be retained because of heavy local interest. Soviet Sociology may be necessary in collections whose users have a particular interest in the USSR.

3. A little-cited periodical might be kept if its price is low.

4. A periodical may be kept because it is useful for purposes other than research. Scientific American is not often cited by 
high-level researchers, but they may read it and obtain good ideas from it. Newsletters and other updating devices also have uses that are not measured by citation counts. A library may consider retaining Consumer Reports for a somewhat different reason: it may be worthwhile for the general interests of the academic community.

5 . There may be political reasons why a little-cited journal should not be dropped. If a local dignitary is on its editorial board, it might receive special attention before being deselected.

6. There may be some journals that ought to be retained even though they are not cited and there is no solid reason to think that they will be of any importance in the next five years. Perhaps there is a belief that topics covered will catch the public or scholarly eye. This is not to say that ESP ought to be trusted, but in most large libraries there surely is some leeway for hunches of this kind.

7. Usually it is best not to eliminate too many periodicals in any one subject field at one time. The number of citations made per article will vary from discipline to discipline. One question should be: is this journal in a field where citations are made sparingly? If so, then individual citations probably have greater significance.

8. Naturally, a young journal may be spared.

After the list of little-cited journals has been pruned according to local needs, the results can be submitted to users for review. It is interesting to see the hostility that some faculty have to the cancellation of subscriptions. ${ }^{21}$ Facts about low citation counts ought to have considerable weight. If academic colleagues around the world are not citing these periodicals, there must be serious questions about the scholarly importance of their contents.

Citation counts of the JCR type are much simpler to use and more economical to conduct than most library use studies. They have the great advantage of allowing staff to concentrate on the most likely candidates for deselection. Though a library may retain some little- or never-cited journals, it can recognize citation evidence as an indicator of the relative value these journals have. At this point the library can refer to its own policies and decide which of the little-cited should be retained.

\section{REFERENCES}

1. Some representative papers on the general topic are: Jeffrey Broude, "Journal Deselection in an Academic Environment: A Comparison of Faculty and Librarian Choices," Serials Librarian 3:147-66 (Winter 1978); Colin R. Taylor, "A Practical Solution to Weeding University Library Periodicals Collections," Collection Management 1:27-45 (Fall/Winter 1976/77); W. M. Shaw, Jr., "A Practical Journal Usage Technique," College \& Research Libraries 39:479-84 (Nov. 1978); J. A. Urquhart and N. C. Urquhart, Relegation and Stock Control in Libraries (London: Oriel, 1976), 154p.; Colin Cayless, "Some Quantitative Methods for Determining the Utility of Periodicals in an Academic Library," in Phillip Watson, ed., Profiling a Periodicals Collection: A Seminar for College of Advanced Education Libraries on Collection Evaluation and Rationalisation (Melbourne, Australia: Footscray Institute of Technology, 1979), p.43-60.

2. A. M. Woodward, Factors Affecting the Renewal of Periodical Subscriptions (London: Aslib, 1978), p.47-48.

3. "Introduction," SSCI Journal Citation Reports, 1982 Annual (Philadelphia: Institute for Scientific Information, 1982), V.6, p.8A.

4. Ibid., p. 73.

5. Ibid., p.83-84.

6. Colin Taylor, "Practical Solutions to Weeding Periodicals Collections," in Watson, ed., Profiling a Periodicals Collection, p.65.

7. With regard to citation data as a correlate of data on use in local libraries, one of the strongest judgements against such an association is made by Pauline A. Scales, "Citation Analyses as Indicators of the Use of Serials: A Comparison of Ranked Title Lists Produced by Citation Counting and from Use Data," Journal of Documentation 32:17-25 (Mar. 1976). Among those concluding that the two go together is: J. C. Baughman, "A Structural Analysis of the Literature of Sociology," Library Quarterly 44:293-308 (Oct. 1974). Several writers have concluded that the quality of a paper 
is related positively to the number of citations it receives, e.g., J. A. Virgo, "A Statistical Procedure for Evaluating the Importance of Scientific Papers, " Library Quarterly 47:415-30 (Oct. 1977). One of those taking the opposite point of view is Stephen D. Gottfredson, Evaluating Psychological Research Reports: The Dimensions, Reliability, and Correlates of Quality Judgments (Baltimore, Md.: Center for Research in Scientific Communication, Johns Hopkins University, 1977), 44 leaves.

8. Pamela Tibbetts, "A Method for Estimating the In-House Use of the Periodical Collection in the University of Minnesota Bio-medical Library," Medical Library Association Bulletin 62:37-48 (Jan. 1974).

9. Barbara A. Rice, "Science Periodicals Use Study," Serials Librarian 4:35-47 (Fall 1979).

10. Tony Stankus and Barbara Rice, "Handle with Care: Use and Citation Data for Science Journal Management," Collection Management 4:95-110 (Spring/Summer 1982), p.96.

11. Rice, "Science Periodicals Use Study," p.45.

12. Alexander Sandison, "Patterns of Citation Densities by Date of Publication in Physical Review," American Society for Information Science Journal 26:349-52 (Nov./Dec. 1975).

13. Stankus and Rice, "Handle with Care," p.96-109.

14. Ibid., p. 97. It should be noted that, probably because they were measuring the use of the back files of each journal, Stankus and Rice used gross citation counts (the total received by all volumes of a journal as recorded in one year of source journals) along with impact factor (numbers of citations received by articles published in a journal over a two-year span, divided by the number of such articles). In the present paper, the citations received by only the last two years of each journal are considered a better guide, because the problem is to predict the immediate future of each title.

15. Barbara Rice, "Selection and Evaluation of Chemistry Periodicals," Science \& Technology Libraries 4:43-59 (Fall 1983).

16. Stephen E. Wiberley, Jr., "Journal Rankings from Citation Studies: A Comparison of National and Local Data from Social Work," Library Quarterly 52:348-59 (Oct. 1982).

17. Ibid., p. 355.

18. Patricia Stenstrom and Ruth B. McBride, "Serial Use by Social Science Faculty: A Survey," College \& Research Libraries 40:426-31 (Sept. 1979).

19. Gary A. Golden, Susan U. Golden, and Rebecca T. Lenzini, "Patron Approaches to Serials: A User Study," College \& Research Libraries 43:22-30 (Jan. 1982).

20. Paul Metz, The Landscape of Literatures: Use of Subject Collections in a University Library, ACRL Publications in Librarianship, no. 43 (Chicago: American Library Assn., 1983), p.108.

21. John B. Wood and Lynn M. Coppel, "Periodicals Deacquisitions in Academic Libraries: Proceedings of a Seminar," Serials Librarian 3:315-31 (Spring 1979), p.325; M. M. Brennan, "Periodical Cancellations: What Happened at Hull," BLL Review 5:67-73 (Jan. 1977), p.69; Donald Davinson, The Periodicals Collection, rev. ed. (London: A. Deutsch, 1978), p.161. 